\title{
A estruturação das concessões por meio de parceria com particulares autorizados (art. 21 da Lei $\mathrm{n}$ ? 8.987/1995)*
}

\section{Concessions and projects' structuring: Article 21 of Law 8.987/95}

\author{
Carlos Ari Sundfeld** \\ Vera Monteiro*** \\ André Rosilho****
}

\section{RESUMO:}

O estudo analisa os critérios para aplicação do art. 21 da Lei de Concessões, que prevê a autorização para a realização de estudos úteis à futura licitação de concessões.

* $\quad$ Artigo recebido em 21 de janeiro de 2016 e aprovado em 22 de fevereiro de 2016. DOI: http://dx.doi. org/10.12660/rda.v275.2017.71646

** Escola de Direito de São Paulo da Fundação Getulio Vargas, São Paulo, São Paulo, Brasil. E-mail: carlos@sundfeld.adv.br.

Professor titular da FGV Direito SP. Doutor e mestre em direito pela PUC/SP. Presidente da Sociedade Brasileira de Direito Público (SBDP).

*** Escola de Direito de São Paulo da Fundação Getulio Vargas, São Paulo, São Paulo, Brasil. E-mail: vera@sundfeld.adv.br.

Professora da FGV Direito SP. Doutora em direito administrativo pela USP e mestre pela PUC/SP.

**** Escola de Direito de São Paulo da Fundação Getulio Vargas, São Paulo, São Paulo, Brasil. E-mail: andre@sundfeld.adv.br.

Professor do Programa de Pós-Graduação Lato Sensu da FGV Direito SP. Doutor em direito administrativo pela USP e mestre em direito pela FGV Direito SP. Pesquisador do Grupo Público da Sociedade Brasileira de Direito Público (SBDP) e da FGV Direito SP. 
PALAVRAS-CHAVE:

Concessão - autorização de estudos — Lei nº 8.987/1995 - licitação

\section{ABSTRACT:}

The study analyses the implementation of Article 21 of Brazilian Federal Law of Concessions (Law 8.987/95), which is the general authorization regime for concessions related to projects' structuring.

\section{KEYWORDS:}

Concession - general authorization regime for concession - Law 8.987/1995 - Procurement

\section{Introdução}

A autorização para a elaboração de estudos foi prevista no art. 21 da Lei nº 8.987, de 13 de fevereiro de 1995 - Lei de Concessões:

Art. 21. Os estudos, investigações, levantamentos, projetos, obras e despesas ou investimentos já efetuados, vinculados à concessão, de utilidade para a licitação, realizados pelo poder concedente ou com a sua autorização, estarão à disposição dos interessados, devendo o vencedor da licitação ressarcir os dispêndios correspondentes, especificados no edital.

O dispositivo prevê que o poder público poderá, se achar conveniente, autorizar particulares a realizar, por conta própria (ou seja, sem gasto de recursos públicos), "estudos", vinculados a uma possível concessão e de utilidade para sua licitação, cujos "dispêndios correspondentes" deverão ser ressarcidos por particular eventualmente contratado, na forma do edital.

Os autorizados a elaborar estudos ou projetos com base no art. 21 da Lei de Concessões não estão legalmente impedidos de participar de eventual licitação futura. Essa conclusão decorre do art. 31 da Lei no 9.074, de 7 de julho de 1995 (diploma normativo complementar à Lei de Concessões), segundo o qual "Nas licitações para concessão e permissão de serviços públicos ou uso de bem público, os autores ou responsáveis economicamente pelos projetos 
básico ou executivo podem participar, direta ou indiretamente, da licitação ou da execução de obras ou serviços". O legislador excetuou, especificamente para os casos de concessões e permissões, a regra constante do art. 9º , I, da Lei nº 8.666, de 21 de junho de 1993 - Lei de Licitações, que veda a participação direta ou indireta do autor do projeto básico ou executivo na licitação.

Muito por conta do histórico ainda recente de aplicação da autorização do art. 21 da Lei de Concessões e das características das normas que a disciplinam, uma série de dúvidas ligadas à sua interpretação ainda pende de solução. A persistência dessas dúvidas gera ambiente de insegurança jurídica. O objetivo do presente estudo é, então, enfrentar essas dúvidas. ${ }^{1}$

1 As dúvidas de interpretação do art. 21 da Lei de Concessões foram identificadas a partir da leitura de trabalhos jurídicos produzidos sobre o tema, bem como da única decisão do Tribunal de Contas da União (TCU) que enfrentou o assunto (Acórdão no $1.155 / 2014$, sessão plenária de 7.5.2014, rel. min. Weder de Oliveira, no qual se afirmou a regularidade da seleção da Estruturadora Brasileira de Projetos para a realização de estudos relativos à concessão de portos organizados e arrendamentos portuários. A decisão foi mantida, apesar do pedido de revisão objeto do Acórdão nº 2.732/2015, sessão plenária de 28.10.2015, rel. min. Bruno Dantas).

O presente estudo aparta-se da maioria da doutrina e converge, em grande medida, para as conclusões a que chegou o TCU no citado acórdão, as quais constam do voto condutor da decisão, de autoria do min. Benjamin Zymler. Vale anotar que, por provocação do próprio TCU no mesmo caso, a União editou novo decreto federal para regulamentar o art. 21 (Decreto Federal no 8.428, de 2 de abril de 2015), o qual, por sua vez, está em harmonia com o quanto apresentado neste estudo.

Acerca dos trabalhos jurídicos pesquisados, confira-se a lista de livros e de artigos produzidos no Brasil, que foram consultados pelos autores (pesquisa feita em fevereiro de 2015): BELEM, Bruno Moraes Faria Monteiro. O procedimento de manifestação de interesse como meio de participação do privado na estruturação de projetos de infraestrutura. Fórum de Contratação e Gestão Pública - FCGP, Belo Horizonte, a. 12, n. 135, mar. 2013; CARVALHO, André Castro. Estudo sobre as manifestações de interesse da iniciativa privada/MIPs e os procedimentos de manifestação de interesse/PMIs. In: SUNDFELD, Carlos Ari; JURKSAITIS, Guilherme Jardim (Coord.). Contratos públicos e direito administrativo. São Paulo: Malheiros, 2015. p. 170-188; DAL POZZO, Augusto Neves. Procedimento de manifestação de interesse e o planejamento estatal de infraestrutura. Fórum de Contratação e Gestão Pública - FCGP, Belo Horizonte, a. 13, n. 150, p. 23-33, jun. 2014; GARCIA, Flávio. A participação do mercado na definição do objeto das parcerias público-privadas... - o procedimento de manifestação de interesse. Revista de Direito Público da Economia - RDPE, Belo Horizonte, a. 11, n. 42, abr./jun. 2013; Revista Zênite - Informativo de Licitações e Contratos (ILC), Curitiba, n. 252, p. 143-152, fev. 2015; GARCIA, Flávio; FREITAS, Rafael Véras de. Concessão de aeroportos: desafios e perspectivas. Revista Brasileira de Direito Público - RBDP, Belo Horizonte, a. 10, n. 36, jan./mar. 2012; GROTTI, Dinorá Adelaide Musetti; SAADI, Mário. O procedimento de manifestação de interesse. In: JUSTEN FILHO, Marçal; SCHWIND, Rafael Wallbach (Coord.). Parcerias público-privadas: reflexões sobre os 10 anos da lei 11.079/2004. São Paulo: Revista dos Tribunais, 2015. p. 153176; GUIMARÃES, Fernando Vernalha. Procedimento de manifestação de interesse (PMI). Revista Zênite - Informativo de Licitações e Contratos (ILC), Curitiba, n. 246, p. 749-752, ago. 2014; GUIMARÃES NETO, Mario Queiroz; BATISTA, Adrian Machado. Procedimento de manifestação de interesse (PMI): diálogos com a iniciativa privada. Escola de Governo do Paraná. mar. 2010. Disponível em: <www.escoladegoverno.pr.gov.br/arquivos/File/Material_\%20 CONSAD/paineis_III_congresso_consad/painel_44/procedimento_de_manifestacao_de_ interesse_dialogos_com_a_iniciativa_privada.pdf $>$. Acesso em: 8 set. 2014; MAIA VIEIRA, 


\section{Não há contrato com o autorizado para estudos}

A autorização do art. 21 da Lei de Concessões não institui um vínculo contratual, sujeito às normas gerais próprias das contratações públicas. É ato unilateral pelo qual o Estado promete obter de terceiro, em favor do autorizado, uma recompensa pública, desde que realizadas certas condições. A relação que a autorização instaura entre estado e autorizado não tem natureza contratual, mas sim de colaboração voluntária não vinculante.

Os agentes privados, uma vez autorizados pelo poder público, não são obrigados a realizar e concluir os estudos. Podem desistir a qualquer momento, não sofrendo, por conta disso, qualquer responsabilização ou penalidade, pois não se configura a inadimplência a que se referem os arts. 389 e 408 do Código Civil. Portanto, no regime do art. 21 da Lei de Concessões não há,

Livia Wanderley de Barros; GAROFANO, Rafael Roque. Procedimentos de manifestação de interesse (PMI) e de propostas não solicitadas (PNS) - os riscos e os desafios da contratação na sequência de cooperação da iniciativa privada. Revista Brasileira de Infraestrutura - RBINF, Belo Horizonte, a. 1, n. 2, jul./dez. 2012; MASTROBUONO, Cristina M. Wagner. MIP/PMI - a parceria na relação público-privada. In: BARATA, Rodrigo Sarmento et al. (Coord.). Novos rumos para a infraestrutura: eficiência, inovação e desenvolvimento. São Paulo: Lex, 2014. p. 183-201; MONTEIRO, Vera. Contratação de serviço de consultoria para a estruturação de projeto de infraestrutura: qual o melhor caminho? In: JUSTEN FILHO, Marçal; SCHWIND, Rafael Wallbach (Coord.). Parcerias público-privadas: reflexões sobre os 10 anos da lei 11.079/2004. São Paulo: Revista dos Tribunais, 2015. p. 143-152; PEREIRA, Bruno Ramos. Procedimento de manifestação de interesse (PMI) e assimetria de informação entre o setor público e o setor privado: monólogo ou diálogo público-privado? PPP - Brasil. O Observatório das Parcerias Público-Privadas. São Paulo, nov. 2011. Disponível em: <https://dl.dropboxusercontent. com/u/18438258/PMI\%20e\%20assimetria\%20de\%20informa\%C3\%A7\%C3\%A3o\%20-\%20 PPP\%20Brasil.pdf $>$. Acesso em: 8 set. 2014; PEREIRA, Bruno Ramos. PMI e insegurança jurídica. PPP - Brasil. O Observatório das Parcerias Público-Privadas. São Paulo, 6 nov. 2013. Disponível em: <http://pppbrasil.com.br/portal/content/artigo-pmi-e-inseguran\%C3\%A7jur\%C3\%ADdica>. Acesso em: 8 set. 2014; REIS, Tarcila; JORDÃO, Eduardo. A experiência brasileira de MIPS e PMIS: três dilemas da aproximação público-privada na concepção de projetos. In: JUSTEN FILHO, Marçal; SCHWIND, Rafael Wallbach (Coord.). Parcerias públicoprivadas: reflexões sobre os 10 anos da lei 11.079/2004. São Paulo: Revista dos Tribunais, 2015. p. 207-232; REISDORFER, Guilherme F. Dias. Soluções contratuais público-privadas: os procedimentos de manifestação de interesse (PMI) e as propostas não solicitadas (PNS). In: JUSTEN FILHO, Marçal; SCHWIND, Rafael Wallbach (Coord.). Parcerias público-privadas: reflexões sobre os 10 anos da lei 11.079/2004. São Paulo: Revista dos Tribunais, 2015. p. 177-206; SAADI LIMA, Mário Márcio. O procedimento de manifestação de interesse à luz do ordenamento jurídico brasileiro. Dissertação (mestrado em direito) - Pontifícia Universidade Católica de São Paulo, São Paulo, 2014; SCHIEFLER, Gustavo Henrique Carvalho. A regulamentação e a utilização do procedimento de manifestação de interesse no estado de Santa Catarina comentários a respeito do Decreto estadual n⿳0 962/12. Revista Zênite - Informativo de Licitações e Contratos (ILC), Curitiba, n. 225, p. 1130-1138, nov. 2012; SCHIEFLER, Gustavo Henrique Carvalho. Procedimento de manifestação de interesse (PMI): solicitação e apresentação de estudos e projetos para a estruturação de concessões comuns e parcerias público-privadas. Dissertação (mestrado em direito) - Universidade Federal de Santa Catarina, Florianópolis, 2013. 
para o autorizado, a obrigação de efetivamente concluir, em favor do poder público, a "prestação" (isto é, de entregar os estudos autorizados, ou de entregá-los nessa ou naquela extensão). Não se configura, assim, um contrato de prestação de serviços, pois este suporia a constituição, por um lado, da obrigação de realizar trabalho certo, e, por outro, da obrigação contraposta de pagar a retribuição (Código Civil, art. 594).

O dever do particular é apenas de método, de procedimento: se decidir por contribuir com estudos, deve garantir sua veracidade - isto é, não pode fraudar, não pode fornecer falsos estudos. Trabalhos incompletos e insuficientes, desde que verdadeiros, podem sim ser apresentados sem que o autor seja considerado inadimplente. Por certo, o particular tem o dever de não agir de modo fraudulento. É um dever assumido implicitamente por quem se vale da autorização expedida, e isso pelo fato de se tratar de ato com objeto determinado: uma autorização para entregar "estudos, investigações, levantamentos, projetos", não para entregar qualquer coisa, mesmo falsa. Daí se falar de um dever de veracidade, cujo descumprimento pode levar à responsabilização pelos danos causados ao poder público.

O poder público não tem o dever de manter a intenção de receber os estudos. Nem mesmo após sua conclusão tem o dever de realizar a correspondente licitação. E, caso decida realizar a licitação, não está obrigado a utilizar os estudos elaborados pelos agentes privados. O poder público pode licitamente se apoiar em outra fonte de dados e de informações para concretizar a concessão, sem que nasça qualquer direito de ressarcimento pelos dispêndios havidos, pois o fato de os estudos terem sido descartados desonera o poder público desse compromisso.

O direito ao ressarcimento pelos dispêndios havidos pelo particular só surge caso o poder público decida licitar o projeto de concessão tomando por base os estudos elaborados pelo particular autorizado, se a licitação tiver um vencedor e se a concessão for outorgada. Nesse caso, para o poder público surge o dever de fazer constar do edital de concessão o ressarcimento, dever esse que decorre da lógica jurídica do art. 21. Pela própria letra da lei, pesará sobre o futuro concessionário um "dever de ressarcir", ou seja, de pagar a recompensa ao autor dos estudos. Somente quando celebrado o contrato de concessão emergirá, para o responsável pelos estudos, verdadeiro direito subjetivo (de ser ressarcido).

$\mathrm{O}$ autor dos estudos não tem direito a um preço - isto é, a uma contraprestação equivalente à sua prestação, que seja devida pela simples conclusão desta - mas a algo que juridicamente se caracteriza como 
recompensa, figura que, no âmbito civil, está regulada pelos arts. 854 e seguintes do Código Civil.

O ressarcimento dos estudos, a que se refere o art. 21 da Lei de Concessões, é uma recompensa pública que, por ato unilateral (a lei falou em autorização, ato unilateral, não em contrato, convenção ou fórmula semelhante), o Estado promete obter de terceiro (o concessionário) em favor do autor dos estudos. A recompensa é sujeita a duas condições: que o particular realize prestação útil (estudos aproveitados em licitação) e que certo fim seja alcançado (concessão celebrada). A obrigação do Estado não é de pagar, pois o devedor do ressarcimento será o concessionário (mas o Estado tem responsabilidade subsidiária, pela mesma lógica do art. 439, caput, do Código Civil). A obrigação do Estado é obter fato de terceiro. Assim, juridicamente, o caso é de promessa, feita unilateralmente pelo Estado, de, realizadas certas condições, obter de terceiro, em favor do autor dos estudos, uma recompensa pecuniária.

Como se observa, o vínculo decorrente do art. 21 da Lei de Concessões é muito especial. Isso porque as poucas obrigações jurídicas envolvidas só se tornam exigíveis, de fato, em se verificando uma série de condições sucessivas. O simples fato de o poder público autorizar determinado particular a realizar estudos não impõe, àquele que autoriza, deveres, tampouco cria, para o destinatário da autorização, direitos. Há, quando muito, expectativa de direitos e deveres futuros (tanto para o poder público como para o titular da autorização), que só se materializarão em se verificando um conjunto de condições sucessivas (efetivo uso dos estudos e licitação bem-sucedida). Assim, não há, no caso, a contraposição imediata de prestações e contraprestações - de execução de serviço e de pagamento de preço - que tipifica os contratos administrativos de prestação de serviços (Lei n⿳ำ 8.666, de 1993, arts. 6º e 55).

A autorização do art. 21 da Lei de Concessões, diferentemente de qualquer contrato de prestação de serviços, não gera o direito subjetivo de o poder público obter prestação específica em prazo determinado, tampouco a obrigação de por ele pagar, ou de fazer terceiro pagar, preço previamente ajustado. Logo, não há "a estipulação de obrigações recíprocas", que o parágrafo único do art. $2^{\circ}$ da Lei $n^{\circ}$ 8.666, de 1993, exige para a configuração de um contrato administrativo: nem há obrigação de prestar serviços, nem há obrigação de pagar por eles.

Vínculo jurídico com essas características - relação não vinculante de cooperação para fins comuns, marcada pela mútua assunção de riscos, e gerando simples expectativa de direitos e deveres futuros (dependentes da materialização de condições sucessivas) - não pode ser equiparado a um 
contrato administrativo de serviços. A relação nascida da autorização do art. 21 da Lei de Concessões tem natureza jurídica de compromisso de colaboração.

\section{Escopo da autorização de estudos}

O objeto da autorização do art. 21 da Lei de Concessões é amplo e a administração pode, por meio desse instrumento, fomentar a elaboração de "produtos" muito variados. O legislador, ao delinear dispositivo com essas características, optou por economizar nas especificações legais, permitindo que o poder público fixe, para cada autorização que concretamente vier a emitir, escopo específico, passível de ser modulado (de forma ampliativa ou restritiva) a depender das suas necessidades e pretensões.

Pela lógica da lei, o poder público pode, por exemplo, expedir autorização buscando obter da iniciativa privada apenas uma ideia, um conceito, ligado à futura modelagem da concessão. Se o poder público tem um grande desafio a enfrentar - por exemplo, reurbanizar totalmente área problemática da cidade - , mas ainda não tem uma política pública definida para tanto, nem elementos suficientes para decidir sobre o uso ou não de concessões em sua implementação, é possível que, com base no art. 21, ele busque dos particulares contribuições para a construção dessa política, o que é uma etapa prévia, bem anterior à modelagem de qualquer concessão urbanística. ${ }^{2}$

Caso a administração queira obter esse tipo de "produto", pontual ou preliminar, ela pode, com base no art. 21 da Lei de Concessões, abrir um procedimento de consulta ao mercado, prévia à estruturação completa da concessão. Por esse procedimento, o poder público tem a possibilidade de ouvir a iniciativa privada para colher subsídios para a tomada de decisões específicas, políticas ou técnicas, no âmbito de projeto mais abrangente.

2 Embora não seja impossível, é relativamente improvável que o fornecimento de subsídios privados à tomada de macrodecisões políticas (por exemplo: revisão da política habitacional nacional) dê ensejo ao ressarcimento do art. 21, justamente pela dificuldade em caracterizar vínculo de utilidade de cada um desses subsídios para com cada concessão que venha a ser realizada. Nas consultas ao mercado em que haja poucas premissas e definições do Estado e em que ocorra uma profusão de ideias e propostas, será difícil delimitar com precisão se algum material foi aproveitado na posterior concessão, e em que medida o foi.

Mas o estabelecimento de políticas públicas pode sim envolver nível grande de concreção, inclusive quanto à utilização de concessões, e quanto a suas futuras características, e estudos custeados por particulares podem ser decisivos quanto a isso, dando ensejo a que o edital da posterior licitação preveja o correspondente ressarcimento. 
Mas também pode usar a autorização do art. 21 para o fim mais extenso de obter colaboração na estruturação completa de projetos de concessão bem específicos, e realizar procedimento de estruturação completa da concessão em parceria, em que o particular faz estudos para fornecer todo o amplo leque de subsídios necessários à efetiva realização da outorga (e não simples contribuições específicas para a construção da política pública ou para decisão tópica no contexto mais vasto da modelagem). Nesse caso, sujeito público e sujeito privado cooperarão intensamente para que se chegue à estruturação da concessão por inteiro (envolvendo, por exemplo, estudos de viabilidade; a proposição de minutas; o esclarecimento de temas específicos; a realização de due diligence ou road show; a revisão, como advisor técnico, de estudos apresentados por terceiros), e mesmo para que sejam levadas adiante as providências práticas para viabilizá-la (fornecimento de subsídios para aprovação pelos órgãos internos e externos de controle, por meio de esclarecimentos técnicos; acompanhamento dos processos de consulta, audiência pública e licitação; eventual revisão dos estudos etc.).

As expressões procedimento de consulta ao mercado, prévia à estruturação de concessão e procedimento de estruturação completa em parceria da concessão designam bem tipos ideais de procedimentos possíveis no regime do art. 21 da Lei de Concessões.

Na consulta ao mercado, pode fazer sentido buscar grande participação de particulares, pois a lógica é de uma disputa quanto às melhores ideias para a tomada de decisões específicas; é quase um procedimento de competição entre interessados, com o Estado como árbitro equidistante entre os interesses privados em conflito.

Na estruturação completa em parceria, a situação é outra: o particular interage e dialoga profundamente com o Estado, colaborando com subsídios sucessivos para que o Estado vá fazendo cada uma das milhares de opções necessárias para chegar à modelagem por inteiro e à efetiva outorga da concessão. Nesse procedimento, o particular e o Estado são autênticos parceiros, com o primeiro auxiliando passo a passo o segundo a tomar a generalidade das decisões públicas e providências necessárias à estruturação.

No procedimento de estruturação completa em parceria, o grau de engajamento entre os sujeitos público e privado é bem maior do que no procedimento de consulta pontual ao mercado. No primeiro, o verbo "colaborar" ganha conotação forte. Afinal, espera-se, aqui, que o compromisso de colaboração conduza não a uma ideia ou a um conceito, mas a um complexo conjunto de ideias, conceitos, premissas, metas, estratégias e métodos que, para serem delineados 
e definidos com precisão, exigem alto grau de interação entre parceiros público e privado. É preciso que ocorram cooperação e diálogo entre Estado e particular para a modelagem sair adequada do ponto de vista não só teóricoabstrato, mas também concreto e prático, ajustada às pretensões, necessidades e possibilidades reais da administração, concluindo com a celebração de um contrato de concessão.

A legislação criou três caminhos alternativos à elaboração de projetos de concessão, conferindo liberdade ao poder público para optar por qualquer deles: 1) estruturação do projeto de concessão essencialmente por agentes públicos, sem apoio externo; 2) estruturação do projeto de concessão com o apoio, maior ou menor, de consultores privados contratados (por contrato de prestação de serviços via Lei de Licitações); e 3) estruturação do projeto de concessão com o apoio, maior ou menor, da iniciativa privada autorizada no regime do art. 21 da Lei de Concessões.

Não há, segundo a legislação, caminho preferencial ou em tese mais adequado. Caberá à administração, à luz do caso concreto, decidir se tem condições de modelar o projeto de concessão internamente, ou se, ao contrário, prefere ou precisa de apoio externo. Nessa segunda hipótese, também caberá a ela decidir, com base em critérios de conveniência e oportunidade, se obterá apoio externo por meio da contratação de prestador de serviços (via Lei de Licitações), ou, quando viável, por meio de colaboração privada (via autorização do art. 21 da Lei de Concessões). E, nesse último caso, de optar pela solução do art. 21, caberá à administração resolver se a colaboração privada será pontual e prévia à estruturação, possivelmente pelo recebimento de muitos subsídios de sujeitos diversos, ou se será pela interação profunda com um parceiro privado escolhido, auxiliando na estruturação da outorga por inteiro.

A administração pode obter a estruturação integral de concessões sem despender recursos públicos na elaboração dos estudos prévios, pois o particular autorizado atua por sua conta e risco. O compromisso de colaboração cria estímulos concretos para que o particular trabalhe de modo mais eficiente e produza material de melhor qualidade, visando o sucesso da concessão - do contrário, caso os estudos não levem à concessão (ou não sejam utilizados para a sua licitação), ele não fará jus a qualquer ressarcimento. O compromisso de colaboração abre a possibilidade de a administração selecionar parceiro privado com alto grau de neutralidade em relação à concessão (por exemplo, caso dê preferência aos interessados em realizar estudos que estejam dispostos a abrir mão de participar de eventual e futuro processo licitatório). 
Uma dúvida quanto à autorização para a estruturação em parceria é sobre as atividades que podem ser obtidas do particular autorizado. É viável que a autorização inclua também o acompanhamento, por exemplo, da eventual licitação, com o fornecimento de subsídios, inclusive jurídicos, à tomada de decisões pelo poder público?

A análise dessa questão envolve dois aspectos: o material, quanto ao conteúdo das prestações viáveis ao particular; e o temporal, quanto à etapa em que elas podem ser realizadas.

A permissão do art. 21 da Lei de Concessão é bastante aberta. Do ponto de vista material, a prestação viável é o fornecimento de quaisquer "estudos, investigações, levantamentos e projetos", desde que sejam "de utilidade para a licitação" e "vinculados à concessão". Em consequência, do ponto de vista temporal, os elementos podem ser fornecidos em qualquer das etapas envolvidas até a celebração de uma concessão, desde as mais iniciais (a construção mais abstrata da política pública de concessões para o setor) até as mais próximas da outorga (a elaboração dos projetos, do edital e da minuta de contrato, consultas e audiências públicas, sua aprovação interna e externa, bem como a realização da licitação).

Subjaz também a esse tema a preocupação com a preservação de competências próprias e exclusivas do Estado, não passíveis, portanto, de delegação à iniciativa privada. ${ }^{3}$ A resposta a essa justa preocupação é que o particular autorizado não pode substituir o Estado na prática de atos administrativos, tanto os de conteúdo decisório (decisão final sobre o conteúdo do edital, sobre a habilitação ou inabilitação de licitante etc.) quanto os de conteúdo consultivo (emissão de pareceres com chancela pública, vinculantes ou não, que sejam necessários à tomada de decisões). O particular é simples auxiliar externo, que não pratica atos administrativos, nem substitui quaisquer agentes públicos cuja participação na montagem das decisões públicas seja obrigatória. Ele contribui com subsídios, mas nunca substitui as autoridades públicas.

No regime do art. 21 da Lei de Concessões, a autorização, utilizada com vistas à elaboração de "produto" mais complexo e abrangente (a estruturação completa de concessões), pode abarcar todas as atividades que se destinem a subsidiar a prática de atos pela administração pública, tanto os de cunho decisório

3 Exemplo de atividade não passível de ser atribuída a particulares é a consultoria e o assessoramento jurídico ao Poder Executivo. Por conta do que dispõem os arts. 131 e 132 da Constituição Federal, a Advocacia-Geral da União e as Procuradorias Estaduais e Distrital exercem a representação judicial e a consultoria jurídica (da União, dos estados e do Distrito Federal, respectivamente). 
(por exemplo, análise de impugnações ao edital) como os de natureza opinativa (por exemplo, manifestação da consultoria jurídica pública sobre a legalidade de determinada cláusula do contrato de concessão). Nesse sentido, pode compreender a elaboração de estudos prévios à licitação (de engenharia, de impacto ambiental, geológico, jurídico etc.), o acompanhamento de eventual e futura licitação para o correspondente fornecimento de subsídios, inclusive jurídicos.

Fornecer subsídios (atividade passível de integrar o objeto da autorização do art. 21 da Lei de Concessões) é algo distinto de praticar atos administrativos de cunho decisório ou consultivo, atividades próprias do Estado e impertinentes ao objeto da autorização do art. 21 da Lei de Concessões. Sobre a prática de atos administrativos decisórios ou consultivos, atividades que em alguma medida envolvem o exercício de função administrativa, os agentes públicos detêm exclusividade. Sobre as informações em geral, ligadas ou não a projetos de infraestrutura, obviamente não detêm exclusividade alguma.

O simples fato de o poder público contar com subsídios de terceiros não importa a delegação de funções públicas. Assim, por exemplo, subsídios jurídicos podem ser obtidos sem que isso signifique violação às competências da advocacia pública, do mesmo modo, aliás, que ocorre quando se contrata editora para prestar serviço de pesquisa jurídica online (inegável fonte de informação para a prática de atos administrativos decisórios e opinativos). Informação jurídica, tanto abstrata (sobre o regime jurídico em tese aplicável a uma situação tipo) como concreta (sobre a correta solução jurídica de um caso), pode ser obtida pela administração de particulares. Nenhum agente ou órgão público detém o monopólio das informações de interesse para as deliberações públicas. Mas isso, claro, não dispensa a manifestação da advocacia pública, nas situações em que são cabíveis ou exigíveis, segundo as normativas internas vigentes.

É lícito que o poder público procure informações qualificadas (subsídios) que o auxiliem na prática de atos administrativos, decisórios ou consultivos. E fazê-lo não importa em substituição da advocacia pública ou de qualquer outro órgão de consultoria estatal. A ela permanece a tarefa de prestar as atividades de consultoria e assessoramento ao Poder Executivo, valendo-se, inclusive, de subsídios vindos de terceiros externos ao corpo do Estado. De posse desses subsídios, o Estado, auxiliado por suas consultorias públicas (jurídicas e técnicas em geral), pode avaliar sua pertinência, e considerá-los, ou não, na prática de atos administrativos, decisórios ou opinativos. 
De outro lado, é positivo que o particular que tenha contribuído na modelagem completa da concessão e da licitação - e conheça em detalhe suas características e nuances - acompanhe também a licitação e esteja à disposição para fornecer subsídios.

O sujeito que esteve presente, do começo ao fim, nas discussões e definições do projeto de concessão e de licitação é especialmente qualificado para contribuir com subsídios relevantes na fase de aprovação por órgãos de controle e também de implementação do processo de licitação, seja qual for a área de conhecimentos envolvida, inclusive a jurídica. A expertise pretérita, que tenha demonstrado para ser autorizado a elaborar os estudos, somada à experiência acumulada no curso da estruturação em parceria de todo o projeto de concessão, faz com que seu apoio seja especialmente valioso à administração.

Não há óbice jurídico ao amplo fornecimento de subsídios, do responsável pelos estudos ao poder público, inclusive durante a fase de licitação (passível de compreender, por exemplo, subsídios para a elaboração das minutas de edital e de contrato, ou durante a realização de consulta pública, ou quando da realização de road shows, e ainda na fase de exame e resposta a eventuais impugnações ao edital, e também de análise e decisão dos recursos interpostos por licitantes). ${ }^{4}$

\section{A autorização de estudos não precisa ser sempre precedida de procedimento competitivo e isonômico}

No procedimento de consulta ao mercado, prévia à modelagem da concessão e de sua licitação, pode fazer sentido, em princípio, que a consulta seja ampla, aberta, justamente para que a administração obtenha muitas propostas (muitos projetos diferentes, por exemplo) ou fique bem informada sobre os interesses envolvidos no futuro programa de concessões, para decidir entre eles. O procedimento pode ter algum caráter "competitivo": edital público prévio, abertura para apresentação de candidaturas, prazos semelhantes para elaboração de estudos pelos candidatos aceitos, decisão motivada final quanto

4 Evidentemente, se for permitido que o autorizado responsável pelos estudos participe da posterior licitação, ele estará impedido de assessorar a administração depois da abertura do certame com a publicação do edital, pois faltará a neutralidade exigível para o bom exercício dessa tarefa. Porém, caso desde o início esteja prevista a não participação do autorizado em futura licitação, o problema não se porá. 
a sua aceitação ou não etc. Seria, porém, um excesso afirmar a aplicabilidade, mesmo aqui, por analogia, do regime do concurso de projetos da Lei $n^{0} 8.666$, de 1993 (arts. 22, $\S 4^{\circ}$, e 52), com suas regras estritas de publicidade e julgamento objetivo. É que existem diferenças importantes entre as situações.

No concurso, escolhe-se um ganhador, que faz jus ao prêmio (que é o preço do trabalho escolhido, cedido à administração), levando a um contrato, o que não existe no caso da autorização do art. 21. Ademais, pelas características dos procedimentos licitatórios da Lei n⿳0 8.666, de 1993, o concurso acabou por ser um procedimento algo rígido, sem interação entre a administração e os proponentes, o que, por exemplo, impede - ao menos torna duvidosa uma fase de negociação com alguns dos proponentes, para aprimoramento dos estudos.

Não há por que transpor essa rigidez para o procedimento de consulta pontual ao mercado, feito no regime do art. 21 da Lei de Concessões: não só porque a lei não a impôs, mas também por resultar contraproducente. É uma distorção - e é irrealista em termos de gestão pública - querer reduzir tudo à absoluta objetividade, limitando a discricionariedade de todos os processos decisórios administrativos, vendo como imorais as negociações e as interações diretas entre administração e particulares etc.

Processos licitatórios são úteis e viáveis apenas quando a administração, já tendo uma visão muito clara daquilo que precisa, consegue estipular critérios prévios e objetivos para escolher entre os proponentes e as ofertas que surjam. Nesses casos, sim, pode-se ter um procedimento rígido de competição, com paridade de armas e julgamento objetivo.

Mas, em muitas situações, a ajuda de que a administração precisa é justamente para o desafio prévio de definir suas necessidades - de modo que não há como publicar um edital com definição clara e precisa do objeto da disputa (como a Lei no 8.666, de 1993, art. 40, I, exige para os contratos). Ademais, em inúmeras situações da vida administrativa não há como circunscrever com critérios exatos o universo de participantes e antecipar o método de julgamento (Lei n⿳0 8.666, de 1993, art. 43, IV e V). É por isso que não se pode, por temor exagerado da discricionariedade administrativa, fazer interpretações ampliativas, ainda que bem intencionadas, para forçar o uso dos processos de licitação para além dos casos, de resto específicos, em que eles são capazes de funcionar bem.

A tentativa de aplicar, para a autorização do art. 21 da Lei de Concessões, as regras ou princípios das licitações é ainda mais inadequada nos casos 
que denominamos de procedimentos de estruturação completa de concessões em parceria. Esses procedimentos servem para a administração interagir com um parceiro escolhido de confiança (ou, no máximo, com poucos parceiros, bem escolhidos, nos casos em que for conveniente dividi-los por especialidades) na concepção por inteiro da concessão e do edital, e no acompanhamento da licitação. $\mathrm{O}$ procedimento de estruturação completa em si não é, nem pode ser, uma disputa, pois é, por natureza, um meio para a ação colaborativa de parceiros, o Estado e o particular. De modo que nada da lógica dos processos competitivos seria pertinente nessa fase.

Não há fundamento jurídico para exigir que a administração abra a possibilidade de quaisquer interessados aptos fazerem e apresentarem estudos para aquilo que estamos aqui chamando de estruturação completa da concessão. $\mathrm{O}$ árduo trabalho de estruturação completa e definitiva não pode ser feito em processo no qual diversos interessados disputem igualitariamente, desenvolvendo estruturações simultâneas. Esse tipo de trabalho exige parceiro único.

E quanto à escolha prévia do parceiro - a qual deve ser orientada pelo interesse público, claro - , faz sentido exigir sempre um processo administrativo, ademais inspirado nas estritas regras ou princípios de licitação?

A administração pode, em algumas situações, optar por uma escolha em procedimento público, com alguns critérios predefinidos. Mas não há um direito subjetivo geral à participação nesse tipo de disputa, nem éilícita a escolha a partir de busca e negociação direta com potenciais parceiros, tampouco inviável escolher os parceiros com critérios não objetivos (discricionários). A crítica às escolhas discricionárias de parceiros só seria possível, da perspectiva jurídica, se a autorização do art. 21 da Lei de Concessão fosse uma autêntica contratação.

$\mathrm{O}$ art. 21 da Lei de Concessões não exigiu processo do tipo licitatório para a escolha do sujeito que, devidamente autorizado, vai se transformar em parceiro privado da administração na estruturação completa da concessão. Não é lacuna desse artigo - fruto de esquecimento e descuido do legislador - a ausência de determinação expressa de que a autorização depende de prévio processo competitivo e isonômico. Lacuna, no direito, é a ausência de norma legal necessária. Não há, no caso, lacuna. O legislador, ao editar dispositivo com essas características, fez uma escolha; criou, para a administração pública, verdadeiro campo de discricionariedade, permitindo-lhe imprimir características variadas aos procedimentos administrativos ligados à 
aplicação do art. 21 da Lei de Concessões. O caso é de discricionariedade a qual, por definição, consiste na abertura, pela própria lei, de espaços de escolha para o gestor público.

É verdade que a autorização deve ser precedida de algum tipo de análise ou procedimento. Trata-se de requisito para conferir transparência e legitimidade à ação estatal, evitando, com isso, desvios ou arbitrariedades. Mas isso não quer dizer que o procedimento deva ser do tipo competitivo e isonômico. A legislação não exigiu procedimento com essas características - e fez bem.

Deixando o plano puramente legal, não há como defender a obrigatoriedade desse procedimento como meio de evitar uma sabotagem ao "princípio universal da licitação", que existiria na Constituição de 1988. A licitação não é princípio, muito menos princípio universal, pois a Constituição não previu um dever geral de licitar para o estabelecimento de qualquer tipo de vínculo jurídico entre poder público e particulares. ${ }^{5}$ Apenas os contratos (e, mesmo assim, nem todos os tipos de contratos, mas só os mencionados pela Constituição) estão sujeitos ao dever de licitar.

Da Constituição podem ser extraídos princípios jurídicos mais abrangentes, especialmente os da igualdade e da boa administração. Mas eles são muito genéricos e abstratos, não gerando o efeito concreto de exigir licitações, ou processos semelhantes, em casos não previstos pela própria Constituição. Não há nesses princípios base suficiente para a construção da regra - de resto irrealista - de que processos competitivos e isonômicos prévios seriam obrigatórios para quaisquer relações e vínculos do Estado com a iniciativa privada.

É impossível, em abstrato, dizer que licitar (ou realizar processo competitivo e isonômico) seja melhor - ou mais justo, correto, eficiente, adequado etc. - do que não licitar (não realizar processo competitivo e isonômico). A comparação entre esses tipos jurídicos ideais e opostos é impertinente, pois são necessários ou úteis em situações diferentes. Não há preferência de um em detrimento do outro; ambos são em tese constitucionais, legítimos e talhados para promover o interesse público - em circunstâncias diversas, é verdade.

Não é só por meio de processos competitivos e isonômicos que são cumpridos mandamentos constitucionais e realizados valores públicos. Há outros

5 Nesse sentido, ver: SUNDFELD, Carlos Ari; ROSILHO, André. Onde está o princípio universal da licitação. In: SUNDFELD, Carlos Ari; JURKSAITIS, Guilherme Jardim. Contratos públicos e direito administrativo. São Paulo: Malheiros, 2015. p. 19-38. 
mecanismos, procedimentos e soluções, para além dos competitivos, que também se ajustam ao Texto Constitucional. ${ }^{6}$

A autorização do art. 21 da Lei de Concessões pode ser firmada a partir de outros critérios e métodos de interesse público, não necessariamente por processos competitivos e isonômicos. Há, assim, espaço de discricionariedade para a administração.

Processos competitivos e isonômicos não são panaceia. São úteis a algumas situações e circunstâncias, mas não a todas elas. É preciso ver que esse tipo de procedimento traz consigo custos elevados - por exemplo, o de receber, avaliar, processar, comparar documentos e propostas muito distintas para, ao final, decidir. Ademais, nem sempre essa dinâmica é compatível com o vínculo que se quer firmar, tampouco com o objeto que se pretende obter. Nesses casos, quando a legislação permitir, o mais adequado é que outros tipos de procedimentos sejam realizados.

\section{Não há direito subjetivo à autorização de estudos. A administração pode autorizar um único interessado}

É exagerada a interpretação de que se deveria, sempre, autorizar todos os interessados em elaborar estudos "vinculados à concessão, de utilidade para a licitação", desde que atendam a requisitos mínimos de qualificação previamente fixados.

A ideia de que quanto mais estudos forem desenvolvidos, mais informações se terá para realizar a concessão é um erro. Nem mesmo do princípio da igualdade decorre o dever de o poder público admitir a apresentação de múltiplos projetos e estudos elaborados pela iniciativa privada, para depois escolher entre eles. $\mathrm{O}$ art. 21 da Lei de Concessões não criou direito subjetivo aos interessados em elaborar estudos.

O instrumento do art. 21 da Lei de Concessões também gera custos ao poder público. Por isso, exigir que o poder público estabeleça, com a iniciativa privada, o maior número possível de relações de colaboração importaria em obrigá-lo a suportar custos elevados e indeterminados toda vez que quisesse

6 Sobre o assunto, SUNDFELD, Carlos Ari. Procedimentos administrativos de competição. In: DI PIETRO, Maria Sylvia Zanella; SUNDFELD, Carlos Ari (Org.). Doutrinas essenciais: direito administrativo. São Paulo: Revista dos Tribunais, 2012. p. 41-49. 
se valer do art. 21 da Lei de Concessões para obter subsídios da iniciativa privada relativos a projetos de concessão.

É falsa a impressão de que as autorizações geram custos só aos privados. Embora o poder público, de fato, ao estabelecer colaboração com base no art. 21 da Lei de Concessões, não gaste recursos (financeiros e humanos) para elaborar os estudos em si - esses custos ficam com o particular autorizado - , gasta recursos para acompanhar o desenvolvimento dos estudos - em menor grau, em se tratando de procedimento de consulta prévia ao mercado, e em maior grau, em se tratando de procedimento de estruturação completa da concessão em parceria - e, também, para analisá-los, em momento posterior, e deles se apropriar.

Há um tanto de ingenuidade na visão segundo a qual a autorização teria custo zero para o poder público, pois ele terá, no mínimo, que destacar grupo de servidores (que custam dinheiro público) para analisar, conferir, comparar, testar e combinar os estudos produzidos pela iniciativa privada. Ao término de todo o processo, esse grupo de servidores também terá de decidir se e como os aproveitarão na eventual e futura concessão. Não basta, assim, que os estudos sejam produzidos por terceiros; para que sejam de alguma utilidade para a concessão, é preciso que o poder público ao menos processe, avalie e absorva todo o material elaborado.

O cenário de menor custo para a administração (no qual seus esforços em grande medida se concentrariam na posterior análise do material elaborado pela iniciativa privada, e não no acompanhamento de sua elaboração) é em tese possível no caso de uso do art. 21 da Lei de Concessões em procedimento de consulta ao mercado, prévia ao início da modelagem. É que, nele, a administração apenas procura obter ideias, conceitos ou sugestões pontuais e específicas, não sendo tão complexo o trabalho de confrontá-los.

Mas a situação é diversa quando o que o Estado precisa é estabelecer, com a iniciativa privada, parceria para fazer a completa modelagem da concessão, obtendo dela, passo a passo, subsídios para a tomada das milhares e sucessivas decisões quanto ao conteúdo dos projetos, das minutas de edital de licitação e de contrato de concessão etc. Seria irracional tentar uma modelagem em parceria com dezenas de parceiros, pois isso geraria desperdício de tempo, energia e recursos, comprometendo inclusive a qualidade da modelagem.

Não faz sentido que agentes privados repitam, em paralelo, atividades similares, multiplicando despesas para atingir um mesmo fim, que possa ser obtido de maneira mais eficiente, com menos recursos. A economicidade não se projeta apenas para os recursos públicos, mas também para os recursos 
privados despendidos pelos autorizados. O interesse público pode ser bem atendido com a racionalização de recursos privados.

A estruturação completa em parceria é extremamente complexa e exige elevado grau de engajamento e de interação entre parceiros público e privado. O poder público, nessa modalidade da autorização do art. 21 da Lei de Concessões, precisa investir, e muito, no acompanhamento da elaboração dos estudos. Cada detalhe precisa ser discutido na minúcia; cada premissa aventada pelo parceiro privado tem de ser validada com a administração; cada elemento fático conectado ao projeto de concessão precisa ser confirmado com o poder público. O parceiro privado, nesse tipo de procedimento, fornece subsídios para a modelagem por inteiro da concessão e de seu processo de outorga. É preciso, pois, que o ponto de vista da administração se faça presente em todos os aspectos da estruturação do projeto.

É pouco útil, nesses casos, que o particular desenvolva apenas em abstrato os estudos para a estruturação, sem que o concedente acompanhe e direcione os trabalhos, fixando, a cada passo, as premissas e os objetivos, e fornecendo as informações necessárias à concessão real. Estudos desenvolvidos sem interação - baseados em premissas imaginárias, em objetivos abstratos e em informações presumidas - resultam em produtos muito preliminares, com utilidade limitada, que não chegam a fazer a diferença para aquilo que o estado precisa, que é chegar à versão final dos projetos e minutas de contrato e de edital de licitação.

Se a administração autorizar que muitos sujeitos realizem concomitantemente estudos para a futura concessão, ela estará diminuindo os estímulos a que cada um deles invista o máximo para produzir estudos abrangentes e de qualidade. Isso pela razão evidente de que a probabilidade de cada estudo ser aproveitado cai na direta proporção do número de estudos ofertados pela iniciativa privada.

Se a administração precisa de estudos profundos, detalhados, e quer dar estímulos para que o setor privado os ofereça, investindo recursos próprios e assumindo o risco de não ser ouvido nem ressarcido, a decisão racional é restringir o mais possível o número de autorizados, pois assim os riscos de não ser ouvido nem ressarcido são menores. A qualidade da informação que a administração pode obter, no regime do art. 21 da Lei de Concessões, para modelar suas concessões tende a ser maior na medida em que decresce o número de autorizados a fornecê-los. Ao menos quando se trata da estruturação completa de concessão em parceria, autorizar um único estudo, pelo sujeito mais qualificado para fazê-lo, é, em princípio, a opção mais afinada 
com o interesse público. A opção por ampliar o número de autorizações é que precisa ser amplamente justificada, e não o contrário.

\section{Discricionariedade na escolha do autorizado}

Além de o poder público ter discricionariedade para decidir o modo pelo qual irá conferir autorizações para a elaboração de estudos, estabelecendo colaboração com o setor privado, também tem discricionariedade para decidir quais critérios utilizar na seleção de parceiros. Isso não significa que possa fazer escolhas arbitrárias; o exercício da liberdade de escolha é condicionado pelo uso de critérios claros, legítimos e lícitos, mas não há parâmetros legais prévios para balizar essa escolha, nem faz sentido cogitar da aplicação analógica dos critérios de habilitação e julgamento típicos dos processos de licitação.

Isso é especialmente verdade nos casos de autorização para que a estruturação completa da concessão seja feita em parceria com a iniciativa privada.

Em uma seleção entre potenciais parceiros privados já qualificados - ou seja, que tivessem atendido igualmente a requisitos mínimos prévios - seria possível, em tese, que o poder público, pressionado pelo prestígio do "menor preço" para julgamentos na Lei $n^{0}$ 8.666, de 1993, fizesse sua escolha pelo menor dispêndio, ganhando quem aceitasse o menor valor de reembolso. Mas seria um critério ruim, não só porque as atividades em pauta são intelectuais e técnicas - em que o grau e a qualidade do engajamento do parceiro são sempre difíceis de precisar em um instrumento abstrato -, mas também porque a autorização do art. 21 não gera contrato, cujos termos possam definir com mínima precisão, e de modo juridicamente vinculante, o conteúdo das prestações futuras do particular.

Se, nesse tipo de relação, o particular mantém sempre o direito de se desvincular a qualquer momento, sem sanção, ou fazer menos do que cogitou de início, a administração, se de fato quiser um parceiro que dure, deverá dar a ele o máximo, e não o mínimo, de incentivos para que se mantenha engajado e faça investimentos nos estudos. Escolher o particular que aceite o menor desembolso é descartar os que estariam mais dispostos a investir e persistir, para ficar com os que desde o início têm baixo interesse em investir.

Se a administração comprime ao máximo o ressarcimento público ao particular, acaba por afastar os interessados neutros, que não contam com os "recursos extras" - que os potenciais interessados na futura concessão 
estejam dispostos a investir "a fundo perdido", desde que os estudos reflitam seus melhores interesses, mesmo quando contrários às necessidades públicas. Em suma, a decisão orientada pelo menor ressarcimento cria desincentivo ao investimento de recursos próprios pelo particular para, em seus estudos, atender aos interesses públicos, gerando projetos incompletos, de má qualidade ou capturados por interesses de grupos específicos.

Na escolha de parceiro para os estudos do art. 21 da Lei de Concessões, o que vale é a análise das características subjetivas e da confiabilidade do parceiro privado, somada à análise dos incentivos que, em função das circunstâncias, ele tem para atuar de modo neutro. E esses são elementos de aferição sempre discricionária, donde a inviabilidade de submeter a escolha do parceiro aos requisitos objetivos de habilitação e de julgamento da Lei no 8.666, de 1993, e, em consequência, a seu procedimento de disputa igualitário. O sistema dessa lei não funciona no caso, pois não há como objetivar previamente os parâmetros de escolha, nem como decidir tudo em um processo de máxima objetividade.

As escolhas mais objetivas, nesse caso da autorização do art. 21 para modelagem em parceria, parecem ser as piores escolhas. É inevitável confiar no juízo bem orientado do administrador. Essa é uma situação em que os parâmetros e procedimentos preferidos da Lei no 8.666, de 1993 - que reclamam objetividade e igualdade - , não servem. A administração precisa escolher um parceiro, um aliado, alguém capaz de inspirar a máxima confiança de que vai de fato investir, em estudos amplos, de qualidade e isentos, e de que, em seus trabalhos, vai interagir profundamente com o Estado, sendo mais sensível aos interesses públicos do que aos interesses de grupos empresariais específicos.

É uma escolha determinada pelas características subjetivas dos sujeitos disponíveis, e não, como nos casos de licitação de contratos, pelas características das propostas de preço (ou técnicas) que formulem no certame. É que, no caso do art. 21 da Lei de Licitações, essas propostas não existem, já que os estudos virão apenas no futuro, se vierem. Quando autoriza estudos para a modelagem completa da concessão em parceria, a administração está escolhendo um parceiro, um sujeito; não está cotejando propostas de serviços, ou seja, objetos, para optar entre eles. Daí a inviabilidade de orientar essa escolha por uma analogia com o sistema das licitações.

E como, a partir de um juízo discricionário, mas sem resvalar para a pura arbitrariedade, fazer a escolha de parceiros para a modelagem completa de uma concessão? 
Um dos elementos importantes é a qualificação técnica e a experiência do privado, em situações comparáveis. É lícito que se escolha pelo critério da maior competência técnica. Mas isso, pelas razões já apontadas, não atrai a incidência das regras da Lei $n^{0}$ 8.666, de 1993, sobre o modo como, nas licitações, se pode e deve aferir esse tipo de qualificação. No regime da Lei no 8.666, de 1993, a habilitação técnica acabou por ficar praticamente limitada à análise de documentos sobre experiências anteriores e sobre a qualificação formal das equipes, sem que a administração possa avaliar de outro modo mesmo por critérios razoáveis, mas inevitavelmente subjetivos - a eficácia e a confiança que se pode esperar do licitante. Essa opção da Lei no 8.666, de 1993, conquanto tenha desvantagens para o interesse público, justifica-se pelo intento de objetivar ao máximo o exame da habilitação técnica, em coerência com o fato de a licitação ser um processo de disputa entre sujeitos titulares do direito a tratamento igualitário. Mas nada disso se aplica à autorização do art. 21 da Lei de Concessão, de modo que a decisão sobre quem parece ser o sujeito tecnicamente mais adequado para atuar como parceiro pode sim envolver subjetividade e discricionariedade - embora não arbitrariedade.

Para selecionar o parceiro privado, entre um conjunto de potenciais sujeitos aptos, outro critério possível, e bastante adequado, é o da neutralidade. É natural que a administração, para modelagem completa de uma concessão em parceria, escolha o agente da iniciativa privada que se mostre o mais neutro em relação à futura concessão: ou por assumir o compromisso prévio de não disputá-la, ou por não ter vínculos societários e contratuais com potenciais licitantes, ou ainda por não utilizar consultores sujeitos à influência de potenciais licitantes, ou por outras razões concorrentes. Em suma: é normal que, para compartilhar com ela a modelagem de uma concessão, a administração prefira alguém capaz de se alinhar essencial e fortemente com as necessidades públicas - alguém que possa ser um parceiro integral - ao invés de alguém contaminado de algum modo por outras relações.

Ao adotar de partida um critério de máxima neutralidade para fazer sua seleção, a administração está reduzindo o universo potencial de escolha. Mas nem é uma redução arbitrária - pois o critério é inspirado pela necessidade pública, inquestionável no caso - nem é uma redução violadora do direito subjetivo de os terceiros participarem - pois esse direito não existe.

De outro lado, a maior neutralidade não pode ser medida por padrões matemáticos, a partir de elementos totalmente documentais. Pode-se, sim, definir de modo prévio quais são os requisitos para alguém ser considerado minimamente neutro, mas a escolha do mais neutro envolve um último juízo 
inevitavelmente subjetivo, uma percepção discricionária. De modo que, embora se possa instaurar procedimento formal para a escolha, o procedimento jamais será sequer parecido com uma licitação, pois não contará com edital objetivo, decisões objetivas etc.

A legislação, em se tratando de concessões, abre, é verdade, possibilidade, ao autor ou responsável econômico pelos projetos básico ou executivo, de participar, direta ou indiretamente, na futura licitação ou na execução de obras e serviços (art. 31 da Lei Federal no 9.074, de 1995, em regra que excepciona a proibição geral existente para os contratos de obras e serviços, por força do art. 9º da Lei n⿳ 8.666, de 1993). Mas nada impede que, na autorização para elaborar estudos, se dê preferência ao interessado que voluntariamente abra mão de participar da eventual e futura licitação, ficando assim impedido para ela.

Ainda que se interpretasse o art. 31 da Lei no 9.074, de 1995, como conferindo, ao autor do projeto básico ou executivo, o direito subjetivo de participar da disputa pela concessão, isso não seria óbice a que, na escolha de parceiro privado para a fase anterior, de modelagem completa da concessão no regime do art. 21 da Lei de Concessão, a administração opte por não utilizar particular que pretenda disputar no futuro o objeto da modelagem. É uma opção com causa legítima, para garantir o máximo de neutralidade e confiabilidade do parceiro privado, contra os riscos de, mesmo sem malícia, este fornecer subsídios que levem a uma modelagem mais próxima de seus potenciais interesses do que dos interesses públicos gerais.

Note-se que o sujeito protegido pelo art. 31 da Lei no 9.074, de 1995, é apenas o autor do projeto básico ou executivo, sendo exagerado interpretar que a norma tenha conferido direitos (de disputar a concessão) também a quem se tenha engajado em relacionamento prévio mais profundo com a administração, influindo tecnicamente na definição dos múltiplos aspectos da outorga, que vão muito além dos desenhos dos projetos de engenharia. Ademais, o engajamento de qualquer empresa com a administração na fase de estruturação, no regime do art. 21 da Lei de Concessão, envolve sempre ato voluntário, cujas eventuais consequências - como a impossibilidade de disputar a futura concessão, se isso estiver disposto - poderão ser sopesadas pelo particular ao manifestar sua vontade de engajar-se, ou não.

Por se tratar de peça fundamental à modelagem da concessão e por ter preferência na elaboração de estudos, é imprescindível que o poder público possa contar com parceiro privado de sua confiança, em tese menos sujeito a captura por agentes do mercado interessados em disputar e vencer a eventual 
e futura concessão. O critério da neutralidade dá à administração a segurança (ou maior segurança) de que trabalhará em cooperação para a modelagem de concessão com parceiro privado que efetivamente esteja a serviço do interesse público.

\section{Conclusão}

Em resumo, a partir das questões discutidas neste estudo, é possível afirmar o seguinte.

A autorização do art. 21 da Lei de Concessões é ato unilateral pelo qual o Estado promete obter de terceiro, em favor do autorizado, uma recompensa pública, desde que realizadas certas condições. A relação que a autorização instaura entre Estado e autorizado não tem natureza contratual, mas sim de colaboração voluntária não vinculante. São inaplicáveis à autorização, portanto, as normas gerais próprias das contratações públicas, muito especialmente dos contratos administrativos de serviços.

No regime do art. 21, a autorização, utilizada com vistas à elaboração de "produto" mais complexo e abrangente (a modelagem completa de concessões), pode abarcar todas as atividades que se destinem a subsidiar a prática de atos pela administração pública, tanto os de cunho decisório (por exemplo, análise de impugnações ao edital) como os de natureza opinativa (por exemplo, manifestação da consultoria jurídica pública sobre a legalidade de determinada cláusula do contrato de concessão). Pode compreender a elaboração de estudos prévios à licitação (de engenharia, de impacto ambiental, geológico, jurídico etc.), o acompanhamento de eventual e futura licitação para o correspondente fornecimento de subsídios, inclusive jurídicos.

Assim, não há óbice jurídico ao amplo fornecimento de subsídios, do responsável pelos estudos ao poder público, inclusive durante a fase de licitação (passível de compreender, por exemplo, subsídios para a elaboração das minutas de edital e de contrato, ou durante a realização de consulta pública, ou quando da realização de road shows, e ainda na fase de exame e resposta a eventuais impugnações ao edital, e também de análise e decisão dos recursos interpostos por licitantes).

Nem a lei nem qualquer regra ou princípio constitucional dão fundamento à exigência de realização de processo do tipo licitatório, competitivo ou isonômico, para a escolha do sujeito a ser autorizado, até porque esse pro- 
cesso seria inadequado para as decisões que a administração deve tomar, seja na escolha do autorizado, seja na condução e aceitação dos estudos.

A lei conferiu discricionariedade para a administração escolher se emitirá, ou não, autorizações e em quais condições irá firmar compromisso de colaboração com a iniciativa privada. À administração é lícito dar preferência a um só parceiro privado na elaboração de estudos. Essa medida, aliás, é a solução preferível nos casos de estruturação completa de concessão em parceria. Os critérios para a escolha de eventuais autorizados podem ser fixados discricionariamente. Apenas a arbitrariedade é vedada. A maior qualificação técnica, a maior confiabilidade e a maior neutralidade são critérios lícitos e adequados para tanto.

\section{Referências}

BELEM, Bruno Moraes Faria Monteiro. O procedimento de manifestação de interesse como meio de participação do privado na estruturação de projetos de infraestrutura. Fórum de Contratação e Gestão Pública - FCGP, Belo Horizonte, a. 12, n. 135, mar. 2013.

CARVALHO, André Castro. Estudo sobre as manifestações de interesse da iniciativa privada/MIPs e os procedimentos de manifestação de interesse/ PMIs. In: SUNDFELD, Carlos Ari; JURKSAITIS, Guilherme Jardim (Coord.). Contratos públicos e direito administrativo. São Paulo: Malheiros, 2015. p. 170188.

DAL POZZO, Augusto Neves. Procedimento de manifestação de interesse e o planejamento estatal de infraestrutura. Fórum de Contratação e Gestão Pública - FCGP, Belo Horizonte, a. 13, n. 150, p. 23-33, jun. 2014.

GARCIA, Flávio. A participação do mercado na definição do objeto das parcerias público-privadas... - o procedimento de manifestação de interesse. Revista de Direito Público da Economia - RDPE, Belo Horizonte, a. 11, n. 42, abr./jun. 2013.

. A participação do mercado na definição do objeto das parcerias públicoprivadas... - o procedimento de manifestação de interesse. Revista Zênite Informativo de Licitações e Contratos (ILC), Curitiba, n. 252, p. 143-152, fev. 2015.

; FREITAS, Rafael Véras de. Concessão de aeroportos: desafios e perspectivas. Revista Brasileira de Direito Público - RBDP, Belo Horizonte, a. 10, n. 36, jan./mar. 2012. 
GROTTI, Dinorá Adelaide Musetti; SAADI, Mário. O procedimento de manifestação de interesse. In: JUSTEN FILHO, Marçal; SCHWIND, Rafael Wallbach (Coord.). Parcerias público-privadas: reflexões sobre os 10 anos da lei 11.079/2004. São Paulo: Revista dos Tribunais, 2015. p. 153-176.

GUIMARÃES, Fernando Vernalha. Procedimento de manifestação de interesse (PMI). Revista Zênite - Informativo de Licitações e Contratos (ILC), Curitiba, n. 246, p. 749-752, ago. 2014.

GUIMARÃES NETO, Mario Queiroz; BATISTA, Adrian Machado. Procedimento de manifestação de interesse (PMI): diálogos com a iniciativa privada. Escola de Governo do Paraná. mar. 2010. Disponível em: <www.escoladegoverno. pr.gov.br/arquivos/File/Material_\%20CONSAD/paineis_III_congresso_ consad/painel_44/procedimento_de_manifestacao_de_interesse_dialogos_ com_a_iniciativa_privada.pdf $>$. Acesso em: 8 set. 2014.

MAIA VIEIRA, Livia Wanderley de Barros; GAROFANO, Rafael Roque. Procedimentos de manifestação de interesse (PMI) e de propostas não solicitadas (PNS) - os riscos e os desafios da contratação na sequência de cooperação da iniciativa privada. Revista Brasileira de Infraestrutura - RBINF, Belo Horizonte, a. 1, n. 2, jul./dez. 2012.

MASTROBUONO, Cristina M. Wagner. MIP/PMI - a parceria na relação público-privada. In: BARATA, Rodrigo Sarmento et al. (Coord.). Novos rumos para a infraestrutura: eficiência, inovação e desenvolvimento. São Paulo: Lex, 2014. p. 183-201.

MONTEIRO, Vera. Contratação de serviço de consultoria para a estruturação de projeto de infraestrutura: qual o melhor caminho? In: JUSTEN FILHO, Marçal; SCHWIND, Rafael Wallbach (Coord.). Parcerias público-privadas: reflexões sobre os 10 anos da lei 11.079/2004. São Paulo: Revista dos Tribunais, 2015. p. 143-152.

PEREIRA, Bruno Ramos. Procedimento de manifestação de interesse (PMI) e assimetria de informação entre o setor público e o setor privado: monólogo ou diálogo público-privado? PPP - Brasil. O Observatório das Parcerias Público-Privadas. São Paulo, nov. 2011. Disponível em: <https:// dl.dropboxusercontent.com/u/18438258/PMI\%20e\%20assimetria\%20de \%20 informa $\%$ C3\%A7\%C3\%A3o\%20-\%20PPP\%20Brasil.pdf>. Acesso em: 8 set. 2014. 
PEREIRA, Bruno Ramos. PMI e insegurança jurídica. PPP - Brasil. O Observatório das Parcerias Público-Privadas. São Paulo, 6 nov. 2013. Disponível em: $<$ http://pppbrasil.com.br/portal/content/artigo-pmi-e-inseguran\%C3\%A7jur\%C3\%ADdica>. Acesso em: 8 set. 2014.

REIS, Tarcila; JORDÃO, Eduardo. A experiência brasileira de MIPS e PMIS: três dilemas da aproximação público-privada na concepção de projetos. In: JUSTEN FILHO, Marçal; SCHWIND, Rafael Wallbach (Coord.). Parcerias público-privadas: reflexões sobre os 10 anos da lei 11.079/2004. São Paulo: Revista dos Tribunais, 2015. p. 207-232.

REISDORFER, Guilherme F. Dias. Soluções contratuais público-privadas: os procedimentos de manifestação de interesse (PMI) e as propostas não solicitadas (PNS). In: JUSTEN FILHO, Marçal; SCHWIND, Rafael Wallbach (Coord.). Parcerias público-privadas: reflexões sobre os 10 anos da lei 11.079/2004. São Paulo: Revista dos Tribunais, 2015. p. 177-206.

SAADI LIMA, Mário Márcio. O procedimento de manifestação de interesse à luz do ordenamento jurídico brasileiro. Dissertação (mestrado em direito) - Pontifícia Universidade Católica de São Paulo, São Paulo, 2014.

SCHIEFLER, Gustavo Henrique Carvalho. A regulamentação e a utilização do procedimento de manifestação de interesse no estado de Santa Catarina comentários a respeito do Decreto Estadual no 962/12. Revista Zênite - Informativo de Licitações e Contratos (ILC), Curitiba, n. 225, p. 1130-1138, nov. 2012.

- Procedimento de manifestação de interesse (PMI): solicitação e apresentação de estudos e projetos para a estruturação de concessões comuns e parcerias público-privadas. Dissertação (mestrado em direito) - Universidade Federal de Santa Catarina, Florianópolis, 2013.

SUNDFELD, Carlos Ari. Procedimentos administrativos de competição. In: DI PIETRO, Maria Sylvia Zanella; (Org.). Doutrinas essenciais: direito administrativo. São Paulo: Revista dos Tribunais, 2012. p. 41-49.

; ROSILHO, André. Onde está o princípio universal da licitação. In: JURKSAITIS, Guilherme Jardim. Contratos públicos e direito administrativo. São Paulo: Malheiros, 2015. p. 19-38. 